\title{
On the Relation between Form and Substance in Law
}

\section{PHILIP SOPER}

Abstract. In this paper the author deals with some theoretical aspects of Robert Summers' last book (Summers 2006). In particular, he concentrates on the hazy relationship between form and substance in Summers' theory. In order to analyze some major difficulties entailed in the thesis that form and substance are different and independent things, the author discusses three specific questions: (1) the difference between form and substance; (2) the possibility of a form meant to be value-neutral; (3) how to distinguish a form-centered approach from a formalistic approach when one has to interpret a statute. This last question is dealt with through examples taken from two legal decisions.*

\section{Introduction}

It is a pleasure to participate in this celebration of Summers' latest contribution to jurisprudence in his book on Form and Function in a Legal System (Summers 2006). No-one in the history of jurisprudence comes close to matching Summers' efforts over the last half-century to draw attention to the role that form plays in enabling legal phenomena to achieve their purposes. And this book, which caps his contributions in this area of jurisprudence, is not likely to see its equal in any of our lifetimes. But before I turn to the book itself, I want to mention an earlier book by Summers, one that I find particular pleasure in reading and re-reading and have often used in my own courses and work on jurisprudence. I am referring to Summers' analytical biography of Lon L. Fuller-one of the series of profiles on famous legal theorists published nearly 25 years ago by Stanford University Press (Summers 1984). Lon Fuller, of course, was a giant in jurisprudence in the generation that preceded both Summers and myself. In fact, we were both students of Fuller at different times at Harvard law school. Fuller's book, which bears some similarities to themes

\footnotetext{
* Abstract by Marco Goldoni.
} 
in Summers' book, became the subject of a number of critical reviews. Summers, in recounting this history, tells the story of Fuller's response when he saw these reviews. "They have attacked my book," Fuller said, "and it shall not go unnoticed," whereupon he turned and strode fiercely up the steps of Langdell Hall (ibid., 12). I mention this incident because I hope that Summers, who I am sure is equally capable of fiercely defending any attack on his book, will not view my brief comments today as an attack. Unlike Marc Antony, who said he came to bury Caesar when in fact he came to praise him, I come honestly to praise, not to bury or attack.

But praise, like legal phenomena, comes in many forms. One mark of a successful contribution to academic thought is the extent to which it provokes questions as well as provides answers. I shall take my cue from this thought and concentrate on questions that are provoked by Summers' book, in particular questions about the relation between form and substance in law. ${ }^{1}$ Summers suggests that these are different things and that they are independent: "That it is usually possible to differentiate relatively sharply between the overall form of a functional legal unit and its material or other components" (Summers 2006, 61). At the same time, however, he mentions that form usually has "complementary" content, and that form leaves its "imprints" or "effects" on content (see, e.g., ibid., 58 inter alia). Sometimes, he adds, there may be "synergistic" effects between form and substance (ibid., 386-7). All of these descriptions of the relation between form and substance are, at best, quite vague and leave many questions for readers who are trying to evaluate the basic overall thesis that form deserves more credit for ends achieved through law. This thesis about the importance of form - that it is "superior" (ibid., 74) and "primary" to other approaches, which by comparison are "ancillary and supplemental" (ibid., 77 ) is the major thesis of the book. ${ }^{2}$ But any attempt to evaluate this thesis

${ }^{1}$ I am aware that Summers eschews using the more common term "substance" as the term to contrast with "formal": Summers 2006, 61-3; but it is not clear to me that there is any real difference in the various terms used to designate the "non-formal." "Material," or "complimentary material and other components," or "content," or "policy," or "substance," all seem equally apt ways of attempting to name the contrast to the "formal." Moreover, Summers himself seems unable to avoid using the more common term on occasion to distinguish the formal from the non-formal. Thus he describes "form-skeptics" as those who believe that form can be reduced to "policy" or other "substantive" content (ibid., 179, 238). And he sometimes contrasts the "formalistic" with the "substantivistic" (ibid., 29, n. 91). The desire to avoid the more common term may arise in part from a concern to avoid conveying meanings one does not intend; but that advantage comes at the cost of confusion when new terminology competes with the more familiar to describe what appears to be roughly the same phenomenon.

2 Summers extolls the virtues of a form-oriented approach in contrast to two main alternatives. The first alternative is a rule-oriented approach. The second alternative (exemplified by "form-skeptics") focuses primarily on substance or policy in a way that fails to accord sufficient credit to form. Summers is explicit in insisting that a form-oriented approach is "generally superior" to the first alternative (ibid., 74, 77), and he argues at length, against the form-skeptic, that form, in contrast to substance or policy, plays more than a merely minor 
leads immediately to two major questions: 1) Exactly what is the difference between form and substance? and 2) How do these two things interrelate? The latter question leads to several subsidiary questions: a) Is it possible that form always follows substance, so that credit is really due mainly to substance? b) Is it possible that form itself often has a substantive content and for that reason is important? c) Is it possible that form is being elevated over substance for the wrong reasons-reasons that explain why the accusation that one is putting "form over substance" is generally regarded as pejorative? In what follows, I briefly consider these questions and indicate how they are provoked by the arguments Summers makes for the credit due to form.

\section{The Distinction between Form and Substance}

\section{A. Does Form Follow Substance?}

The distinction between form and substance traces at least to Aristotle who used the term to draw attention to the purposive arrangement of human artifacts in explaining their causal origins. Summers acknowledges the "technical philosophical" meaning to be found in Aristotle's discussion (ibid., 47), but seems to prefer as a better explanation what he calls "the most common use of the word in English" in which " form' means the visible contours or shape of a physical thing." (ibid., 50). Consider, e.g., a vase made of clay. Aristotle would have explained that to fully understand the origins of this object, one needs to distinguish, not only the material cause (the clay), but also the formal cause (the shape, purposely designed to hold water and/or flowers). This analogy to physical shape as form nicely fits Summers' suggestion that form and substance are independent concepts that can be sharply differentiated. One can change the shape of the vase, while leaving the substance unaltered. Or, one can hold the shape constant and change the substance- the vase can be made of glass or wood or metal. And in both cases the overall purpose (constructing a container that will hold water and/or flowers) becomes the measure of success: Poor form will yield a poor vase, as will an ill-considered substance (a vase made of porous material?).

Compare, now, this commonsense idea of the distinction between form and substance with legal phenomena. Consider, in particular, the example that seems to figure more often than any other in Summers' analysis: that of the legal precept that can have varying degrees of definiteness. Shall we set the speed limit (or the retirement age) at 65 , or shall we set it at "a

role (ibid., 238-40). Thus form is defended, either explicitly or implicitly, as playing a more important role-at least more important than is currently recognized-than either rules or substance. 
reasonable speed" (or age)? Here the form is one of definiteness and the substance is the designated speed limit. Now it is clear that we can keep the form of definiteness constant, while altering the content (changing the speed limit to 55 or 70, as Summers is quick to point out: ibid. 30, n. 95). But note that, unlike the vase, we cannot easily do the opposite: We cannot keep the substantive content $(65 \mathrm{mph})$ the same, while changing the form of definiteness. In the case of the vase, we can see both form and substance as independent, keeping the shape the same while changing the content from clay to glass or vice versa. But in the case of the legal precept, the substantive policy decision $-65 \mathrm{mph}$ should be the maximum speedautomatically carries with it the correlative form. Substance, it seems, carries form in its wake. ${ }^{3}$

\section{B. The Puzzle of Form}

Whether the above suggestion applies to other examples of legal phenomena that Summers discusses is an interesting question, which I shall defer for the moment in order to show how this possibility-that form follows substance-helps explain one of the major puzzles about form that Summers considers at the beginning of his book. The puzzle is this: If form is so important, why has it been neglected and overlooked so long? To put the question another way, how is it possible that we have managed by and large to get along relatively well in the design of legal phenomena without paying explicit attention to form? Summers considers both of these questions early in the book and offers two sorts of answers.

First, Summers lists several reasons that purportedly explain why form has been neglected. Scholars, e.g., 1) have failed to provide an overall definition of form; or 2) have failed to differentiate form from substance; or 3) have taken form for granted (ibid., 11). But these reasons do not seem to be explanations for the neglect, so much as repetitions of the claim that there has been neglect. Explanations must do more than repeat what it is that is to be explained. So we don't know why form has been neglected; we only know that it has been. A second confrontation with this puzzle occurs a few pages later when Summers asks how it is possible to have developed generally well-designed legal phenomena while neglecting the role of form. Now the answer is mainly two-fold: 1) Western systems have developed over a long period of time and have managed, incrementally, to achieve relative success in the design of legal

\footnotetext{
${ }^{3}$ Note that it is Summers himself who suggests that the "policy content" or substance of the speed limit example is the stated rate of speed (ibid., 30). If, on the other hand, one designates as "substance" the more general policy of determining a safe speed, it may be that one can avoid the particular criticism just made-that substance often dictates form-but only by implying that the distinction between form and substance can be manipulated as needed in order to force the distinction one wants to make.
} 
phenomena despite the lack of explicit attention to form; and 2) legal practitioners-judges, lawyers, legislators-may have unconsciously been using form in practice all along, even though the study of form by scholars has been neglected. Notice what these explanations suggest:

1) The fact that we are unconsciously using form in practice supports the possibility that, for the most part, form follows substance. We concentrate on the speed limit, or the substantive policy that we want a particular legal phenomenon to serve, and form follows almost automatically.

2) Second, this view of the relationship between form and substance helps explain why it is that many of the claims about form are "obvious." Summers devotes some time in the early part of the book defending his claims about the importance of form against the charge that the claims are obvious (ibid., 15-6). In the end he does not seem to deny that the importance ascribed to form is often obvious; rather, he defends the possibility that even the obvious may have hidden dimensions that deserve fuller exploration. If the role of form is "obvious," if it is unconsciously incorporated in practice, perhaps the reason is that form, though present and distinguishable from content, is secondary, not primary.

\section{Form as Substance}

I turn now to the possibility that form itself may embrace or entail substantive elements of value. Three questions present themselves here: 1) Is the definition of form meant to be value-neutral (a factual concept), or does it implicitly include moral criteria in deciding what counts as "form?" 2) What substantive consequences does form itself entail-consequences that need to be taken into account in order to know whether form is well-designed? 3) Finally, what is the connection between form and the substantive ends that form helps to achieve?

\section{A. Is "Form" a Value-Neutral Concept?}

Summers repeatedly suggests that form can be both good or bad, well- or ill-designed for the purposes it is intended to achieve. This suggests that "form" is intended to be a factual (neutral) concept, not a moral concept. But doubts about whether this is in fact his intention are raised at the very outset. "Form" is defined as the "(i) purposive, (ii) systematic, (iii) arrangement" of legal phenomena. But why do we need all three of these ideas? The first (purposive) and third (arrangement) are easy to understand. Consider again the example of the vase. Beginning with the material element (clay, glass, or metal), one understands that the "arrangement" of this material is a way of drawing attention to its shape or form. So, too, in order to distinguish random accidental arrangements from the intentional 
arrangements characteristic of human-designed artifacts, we need to add that the arrangement is "purposive": The arrangement is purposely designed to achieve certain ends-the clay is shaped in order to hold water and/or flowers. But what does "systematic" add to these two ideas? What would it mean to purposely arrange clay material in the shape of a vase but in an unsystematic way? Isn't that just another way of suggesting that the form is ill-designed, sloppy, not well-suited to the end? If so, then "systematic" is serving indirectly as a value element that incorporates notions of good design into the very definition of form. The clean division between the idea of form, which can be either good or bad, is muddied by refusing to count as "form" those arrangements that are insufficiently "systematic." Summers reinforces this conclusion in his own explanation for why "systematic" is necessary to the definition. He explains that "systematic" refers to the relationship among parts of an arrangement and denotes a requirement of "consistency" among the parts (ibid., 42). The example he gives is of a legislature that is too large and unwieldy to operate efficiently. But "too large" and "unwieldy" are evaluative terms. To purposively arrange a legislative body in a way that is too large still results in a functional legal unit-just one that isn't very well-designed. If we don't count such a unit as having a "form" just because it is unwieldy, we seem to have collapsed the distinction between form simpliciter and good form.

Why is this important? Two consequences follow from making form an evaluative rather than simply a factual concept. First, the credit due to form is lessened to the degree that we have already qualified the definition with a substantive criterion-it is substance, once again, not form alone, that deserves part of the credit for ends achieved. Second, and perhaps more seriously, the inclusion of evaluative criteria into the definition of form can lead to misleading characterizations of legal phenomena. Consider, e.g., the form of a court. Though Summers does not subject this institution to the same form-oriented analysis as other functional legal units, he does suggest that an essential formal feature of a court, in contrast to a legislature, is the court's "dialogic" procedure (ibid., 56). In order to make relevant factual findings and apply the law, the court, unlike a legislature, must give both sides an opportunity to be heard. But surely we cannot refuse to count an institution as a court if, instead of proceeding "dialogically," it proceeds to inquire and investigate on its own, without input from the parties. The adversary system is not the only form of a court in Western societies, as the dominance of inquisitorial systems in civil law countries makes clear. Here, then, is a possible example of how a preference for a particular type of court (the adversarial) can be incorporated as a value judgment into the very definition of form, leading to a misidentification of the formal features of a court in general. 


\section{B. The Substantive Consequences of Form}

Whether a particular form is well- or ill-designed is determined by how well it serves the purposes of the particular legal phenomena that it embraces. For the most part, Summers provides an illuminating account of the difference that form can make in achieving such purposes. I raise here only one possible critique concerning the consequences of particular forms that may have been overlooked. Consider, again, the repeated example of the difference that the form of definiteness makes in choosing between a specific rule (e.g., $65 \mathrm{mph}$ speed limit) as opposed to a more general principle (drive at a reasonable speed). Summers provides an elaborate analysis of the factors that might determine whether to choose the more definite speed limit as opposed to a more general discretionary standard of "reasonable speed" (ibid., 190-9). But the policy considerations that figure in the analysis focus exclusively on the obvious factors of "safety, timeliness of flow, and driver choice." Missing in the analysis is the major critique of the critical legal studies movement that suggests that definiteness in legal precepts favors the sophisticated and well-to-do over the less well-educated and vulnerable classes of society (Kennedy 1976). Adding this consideration into the analysis could reveal the potential of particular forms to generate substantive effects, both positive and negative, on their own accord-competing with the policy objectives that underlie the legal norms.

\section{Form's Influence on Substance}

One final question about the substantive implications of form is raised by Summers' repeated suggestion that good form can beget good content or substance. For example, "definiteness and clarity of expression in a draft rule facilitate scrutiny and may lead to improvements in content" (Summers 2006, 204). Now this question of the connection between form or procedural principles, on the one hand, and substantive content, on the other, has a long history. It became in many ways the most contested issue raised by Fuller's book, previously mentioned, which similarly claimed that adherence to certain procedural values requiring clarity in the law would establish minimal moral values in law. H. L. A. Hart, almost uncharacteristically caustic, attacked Fuller's claim, which was similar to the one Summers makes: "There is [. . . no special incompatibility between clear laws and evil. Clear laws are [...] ethically neutral though they are not equally compatible with vague and well-defined aims" (Hart 1965, 1287). Where does Summers stand in this argument about the connection between clarity in form and goodness of content? On the one hand, Summers is careful to qualify his claim by suggesting only that good form "tends" to beget good content (Summer 2006, 204). And he is quick to point 
out that well-designed form may be combined with bad policy or other content, citing the example of our own pre-Civil War American Fugitive Slave Act (ibid., 205). On the other hand, when Summers returns to the connection between form and substance in a later chapter on the rule of law, the qualifications appear to have been dropped. Adherence to the principles of the rule of law is claimed to realize a wide variety of substantive values, including those of "legitimacy, justice, freedom, dignity, democracy, and rationality" (ibid., 341). It would advance our understanding of how Summers understands the connection between good form and good content if we knew the strength of the claim, as well as the assumptions about human nature on which it is based. We still have in the modern world, long after the end of our own examples from the period of slavery, many examples of regimes that have clear laws that are welldesigned to communicate legal norms the content of which, however, seems woefully lacking in respect for human freedom and dignity.

\section{Form and Formalism}

I turn now to one final question about form. Summers carefully distinguishes "form" in his sense from the "formalism" that has been the subject of so much attack as a method of judicial interpretation. "Formalistic interpretation," in the sense of "wooden literalism," is a vice that Summers condemns as well as others; and, he insists, nothing in his own emphasis on the importance of form leads to, or encourages such, literalist approaches to interpretation. Summers provides an illuminating example of this vice in a case posed by Cicero. In that case, a court had to interpret a marine salvage statute that awarded any ship in distress that had been abandoned by its owners to any sailor who "stayed with the ship." In the case before the court, the sailor had been sick and thus unable to escape the floundering ship. After the ship luckily made it to safe shores, the sailor, who had done nothing to insure the ship's safety, claimed the ship under the statute and the Court awarded it to him. Summers rightfully criticizes this case as an example of "wooden literalism." Surely it makes most sense to interpret the salvage statute as awarding the ship to those who "stay with the ship in order to save it" (ibid., 276-8).

The problem with this explanation of the vice of formalism is that it stands in rather marked contrast to other features of the book that seem to emphasize the importance of language in interpretation. In his survey of interpretative methodologies, for example, Summers argues for the priority of a "language-oriented criterion as the primary criterion of interpretive faithfulness" (ibid., 257). This focus on language is preferred to one that takes context and purpose into account, or one that looks for legislative intent. Similarly, we have already seen how often Summers favors definiteness and clarity as a form for precepts, even claiming that such form 
begets good content. Finally, on at least two occasions, Summers hints that judicial decisions such as Welsh v. United States, 398 U.S. 333 (1970) (as well as several other cases) are wrongly decided because they are inconsistent with the clear language of the statutes being interpreted (ibid., 24, n. 50, and 29, n. 91). Now Welsh was a case that held that a personal moral code qualified one for conscientious objector status under a statute whose "literal language" required a religious basis for the belief. If this decision is wrongly decided simply because it is inconsistent with the "literal language," how do we distinguish this case from Cicero's? In Cicero's case, we look sensitively to context and purpose and decide that "stayed with the ship," should be supplemented by reading into the statute "if done in order to save it." How can we criticize Welsh, on the basis of the language alone, without also considering context and purpose? Particularly given how difficult it is to define "religion," what better guide is there here to the legislative will than context and purpose-including the possibility that any other construction of the statute would lead to serious constitutional problems (as Justice Harlan's concurring opinion confirmed)? Indeed, the majority's opinion can be read as interpreting the "religion" criterion for qualification to mean "only if no serious constitutional establishment clause issue is thus presented," just as we read the salvage statute to mean the sailor wins only if he stayed "in order to save the ship." ${ }^{\prime 4}$

Two general questions emerge. First, how does one distinguish Summers' preference for language-oriented approaches from the vice of "formalism" that he purports to abhor? If formalism as an interpretive methodology is bad because it is insufficiently sensitive to purpose and context, doesn't that mean that the methodological priorities for interpretation should be awarded to purpose, context, and intent, as well as language (or even that priority should be given to the former)? Second, is there after all something about the emphasis on form that leads to this preference for a language-based orientation? Though Summers denies that there is any such implication, it is curious to find that both "formalism" and "form" share a similar basis in making language, rather than purpose or context, the primary guide to interpretation.

\footnotetext{
${ }^{4}$ Even more striking is another case Summers faults for failing to heed the "clear language" of the statute. In Friends of Mammoth v. Board of Supervisors, 502 P.2d 1049 (Ca., 1972), the court decided that "projects" requiring impact statements included governmental decisions to issue permits for private developments. The majority insisted that "the mere literal construction of a section in a statute ought not to prevail if it is opposed to the intention of the legislature apparent by the statute": ibid., 1057. It is hard to see how Summers can oppose formalism and yet fault this opinion on the basis of language alone without considering the court's argument about purpose and intent in construing the language.
} 
University of Michigan Law School Hutchens Hall Ann Arbor, MI 48109 USA E-mail:psoper@umich.edu

\section{References}

Hart, Herbert L. A. 1965. Book Review of The Morality of Law. Harvard Law Review 78: 1281-96.

Kennedy, Duncan. 1976. Form and Substance in Private Law Adjudication. Harvard Law Review 89: 1685-778.

Summers, Robert S. 1984. Lon L. Fuller. Stanford, CA: Stanford University Press. Summers, Robert S. 2006. Form and Function in a Legal System: A General Study. Cambridge, MA: Cambridge University Press. 